\title{
INFECTION IN INFANCY *
}

\author{
BY \\ ROBERT CRUICKSHANK, M.D., M.R.C.P., D.P.H. \\ Pathologist, L.C.C. Group Laboratory, North Western Hospital, Hampstead
}

I have chosen as my text 'Infection in Infancy' because I believe that paediatricians have a duty (1) to teach students and practitioners to regard the infant not as a 'miniature man' but as a creature with its own and often inadequate way of reacting to infection, and (2) to impress upon a larger public that infection in infancy is closely correlated with malnutrition and poor environment.

It is customary to divide infant mortality into deaths in the first month (neonatal mortality) and deaths between the first month and the first year of life. Neonatal deaths, which constitute more than half of the infant mortality, are mostly attributable, directly or indirectly, to prematurity, with congenital defects and bad obstetrics as additional contributory causes; the bulk of them occur in the first week of life. Death from infection, apart from postasphyxial and aspiration pneumonia, is relatively unimportant at this early stage, and it might be wiser to combine deaths in the first week with the stillbirth rate, for their causes are similar and their prevention is closely linked with better nutrition and supervision of the pregnant woman. Although this is not primarily the responsibility of the paediatrician, he will share in the general satisfaction at the remarkable reduction in the still-birth rate and neonatal mortality during the war years. Stillbirths have fallen from 36 per 1000 in 1940 to 28 per 1000 in 1944 and neonatal mortality from $29 \cdot 6$ to 24.5 per 1000 , an astonishing achievement which must be directly related to the better nutrition of the pregnant women and is to be regarded as one of the major victories of the war.

* The George Frederic Still Memorial Lecture delivered before the British Paediatric Association at Rugby on August 3rd, 1945.

\section{The infant's reaction to infection}

The first and outstanding feature of infection in infancy particularly in the first six months of life, is that it is mostly due to endogenous bacteria; that is, bacteria which ordinarily live as saprophytes in the upper respiratory tract, in the bowel or on the skin, and which in older children and adults have little power to initiate infection. Chief among these are certain pneumococcus types (e.g. types $4,6,19$, 23), the coliform family, the staphylococci and monilia. These bacteria may be transferred from one child to another, and induce infection if dosage is large and resistance is low. The preponderance of a particular pneumococcus type, e.g. type 19, in broncho-pneumonia (Hendry, 1942) or of a coliform organism, e.g. Bact. coli neapolitanum in infantile enteritis (Bray, 1945) can be explained on this basis. By contrast, the exogenous infections (scarlet fever and other streptococcal infections, diphtheria, measles, tuberculosis, even the common cold) are relatively rare although these are all air-borne diseases to which the infant is often exposed. The specific intestinal infections are also uncommon in infancy and only pertussis seems able to break through the early barrier with any frequency.

Defective defences. Endogenous infection in the early months of life is closely associated with overcrowding and poverty, for it is much less frequent in the highest than in the lowest social classes but, given adverse conditions, the occurrence of infection is facilitated by the poor response which the infant's tissues make to invading bacteria of low virulence. This poor response is probably related to the immaturity of the defence mechanism. When older tissues are attacked, there is an immediate outpouring of

TABLE 1

Deaths in Children aged 0 To 5 Years; 1938

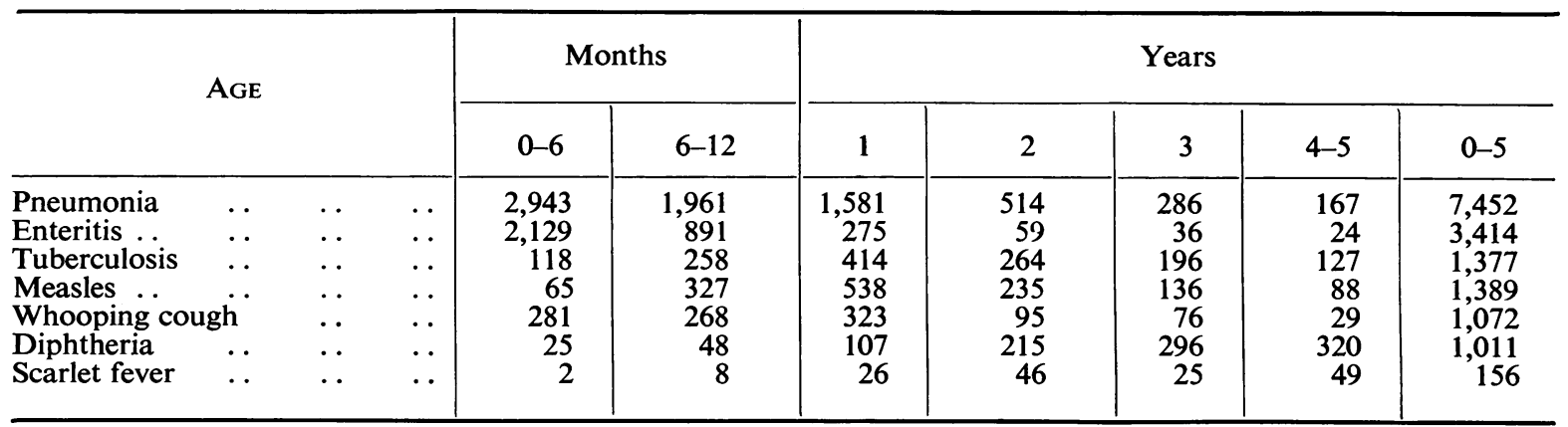


phagocytes-both polymorphonuclear leucocytes and mononuclear or macrophages-followed in a few days by the appearance of humoral antibodies, and the infection is localized and overcome. But the production of phagocytes and antibodies requires efficient factories and the necessary raw material, both of which are inadequately provided by the infant. Thus its leucocytic response contains many immature white cells, and experiment has shown, as indeed is known from the infections that accompany leukaemia, that these immature white cells are poorly equipped to deal with invading bacteria. Macrophages are derived, according to Maximov, from the lymphocyte but lymphoid tissue is poorly developed in the infant at birth and the germinal centres or factories do not become prominent until some months later. The excess of lymphocytes in infant blood probably reflects the constant demand on the lymphoid system to produce these cells and the lymphoid hyperplasia in the early years of life is evidence of the child's response to the many foreign stimuli it receives. Thus enlarged tonsils and adenoids are to be regarded as part of the defence mechanism rather than a menace to health, and it is a sad commentary on medicine that tonsillectomy is, or has been, four times more common among well-to-do than among poor-class children (Glover and Wilson, 1932). Experimental work lends support to the view that lymphoid tissue reacts to bacterial stimuli. Thus guinea-pigs reared in an aseptic atmosphere so that they did not acquire the usual endogenous bacterial flora throve well, but their lymphoid tissue failed to develop normally and there was a complete absence of germinal centres. Young rabbits, injected intravenously with killed bacterial vaccines, showed a rapid and marked development of germ centres in spleen and lymphatic glands.

Lymphoid tissue may also be a main source of antibodies, for after the local injection of viruses or bacteria in rabbits the regional lymph gland and the efferent lymphatics were found to contain a higher concentration of antibody than the blood (Ehrich and Harris, 1942). More recently, the lymphocytes themselves in the efferent lymph vessels have been found to contain four to eight times the concentration of antibody found in the plasma and this was not due to adsorption of the antibody on to the lymphocytes (Harris et al., 1945). Antibodies are mostly concentrated in that part of the plasma protein which is now known as gamma globulin. The plasma protein level is mostly low in the newborn (usually 4 to $6 \mathrm{gm}$. per cent.) and particularly so in premature babies (3.7 to $5.4 \mathrm{gm}$. per cent.) (Hickmans et al., 1943) but detailed analysis has not yet been made of the composition of the infant's plasma proteins. In the newborn calf the globulin content is very low but the calf acquires maternal antibody after birth from the colostrum, whereas the transfer of human antibody is mostly via the placenta and is already in the infant's blood at birth. If, however, an abundant supply of natural antibody should help the infant to cope with endogenous as well as exogenous infections, con- centrated gamma globulin is now available and might well be tried in the treatment of bronchopneumonia and gastro-enteritis.

The lack of reactivity of the infant's tissues helps to explain the anomalous clinical infections seen in infancy: staphylococcal osteomyelitis with little or no localizing signs; staphylococcal pneumonia; coliform infections of lungs and meninges in the first few weeks of life; severe and even fatal monilia infections; fulminating pneumococcal septicaemia detected only by bacteriological examination postmortem. Fortunately the pioneer work of MacGregor (1943) on the etiology and pathology of infantile infection is now being followed in other centres, and the prudent paediatrician is learning to correlate what were puzzling clinical phenomena with the pathological findings. The infant's poor response to infection also helps to explain disappointing results obtained with the new chemotherapies. Anderson's (1943) comparison of deaths from pneumonia in Glasgow in the sulphonamide and pre-sulphonamide periods has shown how important is the host's reaction in overcoming bacterial infection. Thus while deaths from pneumonia in the age-group 10 to 45 during the years 1939-41 were only 40 per cent. of those of the presulphonamide era (1922-38), deaths in infants under one year of age were still 75 per cent. of those of the earlier period and the reduction could probably be ascribed as much to social improvement as to sulphonamide-therapy. As an example of the relative failure of sulphonamides in early infancy, Professor G. B. Fleming has allowed me to quote a case mortality of 48 per cent. among 100 infants under six months of age admitted with primary pneumonia to the Royal Hospital for Sick Children, Glasgow, during the past three years. It will be interesting to see if penicillin-therapy greatly alters this figure.

Immature physiology. Besides the poor response of the defence mechanism to infection the infant physiology is also unstable and immature, and its dysfunction may quickly lead to irreparable damage. It might therefore be profitable if more attention were given to physiological upsets in the respiratory and alimentary systems and in the blood-chemistry as a result of infection, and attempts were made to correct these upsets early rather than late. Thus the baby with respiratory and other infection seems prone to anoxaemia, and oxygen therapy, perhaps combined with helium to help diffusion, should be used earlier and more liberally than it is in many paediatric units; the pathology of the brain of infants dead of infection also needs intensive study. Again, in intestinal infections the inadequacy of the infant's physiological response is obvious. As Miller's (1942) studies have shown, gastric acidity is low in the early months of life and gradually reaches adult level about the end of the first year. The artificially-fed infant drinking contaminated milk is therefore poorly protected against the introduction of foreign bacteria into the bowel, particularly as, in addition, cow's milk 
protein makes greater demands than human milk on its gastric juices. Pyrexia also reduces gastric acidity. The inadequacy of the acid barrier allows colonization of the normally sterile upper reaches of the small intestine with irritating effects on a gut which at the best is none too stable. This intestinal upset may be accompanied by absorption of toxic products to the liver via the portal system with resultant dysfunction of another vital organ. In a series of 31 autopsies on infants with enteritis at the L.C.C. North Western hospital, two-thirds of the cases showed varying degrees of liver damage, compatible with a toxaemia. In a larger series of 100 cases at the Hospital for Sick Children, Great Ormond Street, 71 per cent. showed fatty change which was extensive in 39 per cent. whereas in a control series of similar age, 59 per cent. showed fatty change which was severe in only 18 per cent. of the cases (R. Stern: unpublished observations). In this connexion Gale (1944) found that certain enterococci which were prevalent in outbreaks of neonatal diarrhoea had a high activity in converting tyrosine to tyramine, an amine which is toxic to young rats and probably also to babies who have not yet developed the appropriate detoxicating enzyme. My colleague, Mrs. Tomlinson, has followed up this promising line of research by examining the enzymic activities of a large series of coliform bacilli from infants with enteritis and from normal controls but so far has failed to discover anything comparable to the enterococcus enzyme. Again, in the treatment of infantile enteritis, the first necessity is to relieve dehydration, and the older practice was to give the infant liberal amounts of normal saline or glucose saline intraperitoneally or intravenously. However, the work of Young and McCance $(1941,1942)$ has shown that the infant kidney has a poor capacity for eliminating sodium so that a large addition of salt to the baby's tissues only results in oedema. The hydrating fluid should therefore contain the minimum of sodium consistent with the correction of acidosis from loss of base from the bowel, and a mixture which serves the purpose well is half-strength Hartman solution plus 5 per cent. glucose. As important as hydration is the treatment of shock from which so many infants with gastro-enteritis suffer in varying degree. In such cases half-strength serum or plasma intravenously should follow and alternate with the Hartman solution, and this anti-shock treatment has been of the greatest value in saving the lives of infants with gastro-enteritis. Thus in a series of sixty-nine dehydrated babies treated in this way by Alexander and Eiser (1944) at the North Western Hospital, the fatality-rate was 11.6 per cent. which may be contrasted with a more usual figure around 50 per cent.

I have avoided direct discussion of the etiology of infantile enteritis, but, if it is remembered that this puzzling infection occurs principally among artificially fed infants in poor class urban communities and has its greatest incidence and mortality in the early months of life, my thesis that these early infections are associated with endogenous bacteria would force us to cast strong suspicion on the intestinal group of organisms. The recent summer epidemics in Glasgow and Dublin lend support to the view that contaminated milk may be a precipitating factor for hygienic standards have been lower and flies more prevalent in the war years. A comprehensive study of the rather analogous infection, scours in calves, would probably help in elucidating the etiology of infantile enteritis, and I am glad to say that the Agricultural Research Committee is undertaking such a study.

\section{Infection and nutrition}

I want next to consider how far infection in infancy is related to deficiences, both qualitative and quantitative, in the diet. The close association between malnutrition and infection is well known, but morbidity and mortality rates are apt to be confused. Thus exogenous infections like measles and pertussis are as common among well-fed as among ill-fed children; yet in the age-group one to two years deaths from measles are eighteen times more common in the lowest than in the highest social class. Susceptibility is the same but resistance to established infection is for a variety of reasons very different. Although strictly comparable data on the relative susceptibility to endogenous infection of well-nourished and malnourished children are difficult to obtain, we know that certain deficiencies, more prevalent among the poor, predispose to infection; thus inadequate intake of the more common vitamins makes tissues more susceptible to infections by affecting epithelial surfaces, muscle tone, intercellular cement or bony structure; but there is no evidence that excess of vitamins gives added resistance. Lack of iron and the consequent secondary anaemia, still all too common, also predisposes to infection as Mackay's (1931) studies showed.

We are on surer ground in stating that the underweight child has a poor resistance to established infection, although we cannot surely say why. Thus among 235 children under two years of age admitted to the Royal Hospital for Sick Children, Glasgow, with primary pneumonia the fatality-rate in 181 moderately or well-nourished infants was 39.2 per cent. compared with $72 \cdot 2$ per cent. among 54 poorly nourished children (Cruickshank, 1933). Malnutrition is common among hospital admissions; Graham (1944) found that two-thirds of 295 children admitted to the Royal Hospital for Sick Children, Glasgow, in 1940-41 were under 90 per cent. of their expected weight and one-fifth were less than 70 per cent. of normal. The fatality-rates were 20 per cent. among children over 70 per cent. of normal and 43.5 per cent. in the definitely underfed children. This poor resistance of the under-weight child to established infection is a complex affair which only animal study is likely to unravel. Some progress has been made on the protective value of protein, a deficiency of which is probably the commonest cause of malnutrition in the infant. Rabbits on prolonged protein 
restriction lose the power to produce antibodies and consequently to combat infection, a finding that may have a bearing on attempts to immunize malnourished children in Europe against diphtheria. Again, in a carefully controlled study with pure line mice, Watson (1937) found that a diet which included milk casein greatly increased the animal's resistance to mouse-typhoid, so that skimmed milk may not be an ' unsuitable food for babies' in spite of the label on the tin. Protein restriction also leads to anaemia in animals since haemoglobin is a compound of iron and protein, and my colleague Dr. Gillespie has lately collaborated in an investigation with young rats fed on a lysine-free diet which resulted in anaemia and hypoproteinaemia probably due to a reduction in the labile protein store in the liver. It may be that some of the refractory anaemias in infants and pregnant women will only respond when an adequate diet is prescribed. Anaemia and hypoproteinaemia are common in infants with enteritis, and it therefore seemed rational to try to correct this deficiency and so raise the child's resistance to intercurrent infection by giving it readily utilizable protein in the form of casein hydrolysate. We have been experimenting at the L.C.C. North Eastern Hospital with these amino-acid concentrates, and preliminary trials suggest that when used as supplements to the diluted milk feeds as soon as the diarrhoea ceases, they are acceptable to the infant and hasten convalescence.

\section{Breast versus artificial feeding}

No discussion of the effect of nutrition on infantile infection can avoid analysis of the relative merits of breast and artificial feeding. The merits of breast feeding are rightly pressed but it should be noted that the decline in infant mortality in the past twenty years has been accompanied by a decreased rather than an increased incidence of breast feeding. If, however, the incidence of infection among naturally and artificially fed babies is compared, some striking differences emerge. Grulee and his colleagues (1934) in a survey of over 20,000 infants reported morbidity rates of 37.4 per cent. among wholly breast-fed babies, 53.8 per cent. among those breast fed for a short period, and 63.6 per cent. among wholly artificially-fed babies. In Toronto, among 1500 babies under one year of age admitted to the Children's Hospital with various infections (about three-quarters of them respiratory) only $15 \cdot 1$ per cent. were wholly breast fed, $29 \cdot 1$ per cent. had been breast fed for at least six weeks and 55.7 per cent. were artificially fed from birth (Ebbs and Mulligan, 1942). In comparison, the feeding histories of babies attending welfare clinics were 35.6 per cent. wholly breast fed, $36 \cdot 2$ per cent. partially breast fed and $28 \cdot 1$ per cent. artificially fed. Again in a small group of 54 infants aged one to four months admitted to the Royal Hospital for Sick Children, Glasgow, with primary pneumonia, there were three deaths among thirteen wholly breast-fed cases and 22 deaths among 41 artificially fed or partially breast fed. There were no breast-fed babies among 24 such cases aged four to six months (Fleming, personal communication).

The close association between gastro-enteritis and artificial feeding is well known but a more detailed analysis of the feeding histories of infants with enteritis provides some interesting data. Gairdner (1945) found that among artificially-fed infants, the case-mortality from enteritis was 55 per cent. in 60 cases breast fed for less than one month (but over one month of age on admission) whilst it was only 28 per cent. in 39 babies breast fed for one month or more. Smellie (1939) also reported a fatality rate of 25.9 per cent. among infants with enteritis who had been breast fed for a month or more compared with 70.6 per cent. among infants who had never been breast fed. These are striking figures and immediately suggest that breast feeding for even a few weeks gives the infant some added protection against infection. What is the explanation? Is antibody transferred from mother to infant in the colostrum and milk? In lambs and calves, ingestion of the colostrum provides protection against lamb dysentery and calf-scours, but in these animals antibody cannot pass through the placenta because of the several layers between maternal and foetal circulations. In the human the bathing of the chorionic villi in the maternal blood-sinuses allows natural antibody to pass freely from mother to foetus and this is the main route for the passive transfer of maternal antibody. Human colostrum contains much lower concentrations of diphtheria antitoxin than does the blood, and milk none at all, while there is no demonstrable increase in the antitoxin level of infant's blood as a result of colostrum feeding (Kuttner and Ratner, 1923). Experiments with rabbits which have a similar placental structure have also yielded negative results on the transmission of antibody via the milk, yet Gröer and Kassowitz (1919) claimed that passive immunity to diphtheria was maintained far longer in breast-fed than in artificially-fed infants. The whole problem needs further investigation both experimentally and clinically.

Breast milk is a natural food and, if present in sufficient amount, should satisfy the infant's requirements for a properly balanced diet. The baby who continues to thrive on the breast is presumably getting most of what it needs although more data are needed on human milk analyses including vitamin-content. It is certainly remarkable that deficiency diseases like rickets, scurvy and nutritional anaemia are rare or mild in breast-fed babies, and the possibility that the appropriate minerals and vitamins, although present in smaller amount in human than in cow's milk, are more completely absorbed from the gut of the breast-fed baby needs examination. Human curd is more digestible and probably more completely broken down than cow curd, and the reaction of the breast-fed baby's faeces with its homogeneous aciduric flora is much more acid (pH around 5.0) than that of the artificially-fed child which has a mixed bacterial flora and 
a neutral or alkaline stool like that of the adult. Perhaps this more acid reaction favours the absorption of calcium phosphate, iron and vitamins and explains the frequent failure to cure deficiency diseases by vitamin supplements given by mouth to the artificially-fed child.

An impartial analysis of the data available would probably justify the view that in the present social conditions breast feeding by 80 per cent. of mothers for six months would materially reduce both morbidity and mortality rates in infancy. This objective is perhaps more readily attainable than is generally believed. Apart from the maladjustments in the early weeks, the majority of mothers cease to feed their babies because lactation fails for no obvious reason or because of preventible breast infections or general debility (Robinson, 1939, 1941, 1942). Both animal and human studies indicate that continued lactation is largely dependent on adequate nutrition during pregnancy and throughout the feeding period. Thus Mackintosh (1943) in Aberdeen was able to report that of 200 women confined in a private nursing home 80 per cent. compared with only 29 per cent. of a similar number of mothers in a poor class district were still breast feeding their babies at six months. In Canada improvements in the diet of low-income women allowed an additional 15 per cent. to continue feeding their babies for six months (Ebbs and Kelley, 1942).

\section{Infection and environment}

Every analysis of infant mortality shows how closely high death-rates are correlated with poor social conditions. It is difficult to disentangle the adverse environmental factors-overcrowding, bad housing, poor hygiene and way of life-which contribute to infant morbidity and mortality from infection. Such studies as those of Titmus (1943), the Wrights (1942) and the Scottish Report should be read more widely by medical men, for the remedies will be accelerated by all the publicity that can be given to the facts of the case. Our particular concern was pungently put by Florence Nightingale eighty years ago when she wrote that the first requirement in a hospital is that it should do the sick no harm. If residential and day nurseries are included in the term hospital, it is obvious that this requirement is still far from being satisfied. Cross infection becomes a serious problem wherever young children, whether sick or healthy, are brought together. Fortunately there is an increasing consciousness that infants under one year of age should not be admitted to hospital unless they can be nursed in individual rooms and, if the child is under six months, efforts should be made to accommodate the mother as well. The recently published experience of the Pickerells (1945) is convincing. In a suburban house converted to a nursing home to accommodate twelve mothers and children, they had no case of secondary infection in a threeyear experience of the surgical treatment of congenital defects like hare-lip, cleft palate and hypo- spadias. The remarkable figures from the Cradle for Foundlings at Evanston where the infant casemortality was reduced from 5.8 per cent. to 0.8 per cent. bear tribute to the value of a rigid isolation and antiseptic technique (Sauer, 1935). Nearer home, the post-operative mortality among babies with pyloric stenosis was reduced from 9 per cent. to less than 1 per cent. at the Hospital for Sick Children, Great Ormond Street, after the new hospital was built and more isolation accommodation became available. Even the strict technique of barrier nursing which is practised in fever hospitals is not enough, for among cases of gastro-enteritis admitted to the North Western Hospital the relapse rate in the barrier ward was four times that in the isolation ward where babies were nursed in singlebedded rooms (Alexander and Eiser, 1944).

For cross infections due to exogenous pathogens like the haemolytic streptococcus, the new technique of oiling floors and blankets will greatly reduce the risks, particularly where the load of infection is high and the respiratory mucosa very susceptible as in measles wards (Wright, Cruickshank and Gunn, 1944). The use of aerial disinfectants such as ultra-violet light or chemical substances which are vaporized into the air, will probably prove beneficial in controlling the spread of respiratory virus infections like the common cold and influenza. Thus in a convalescent children's home for long-stay patients Harris and Stokes (1945) reported a ratio of 1:10 of upper respiratory infections in the wards treated with vaporized glycol compared with the control wards. Improved hospital design and equipment in conjunction with an adequate and properly trained nursing staff are, however, the most important requirement to protect the infant against infection. The recent experience of Jacoby (1944) in a unit of 33 beds consisting of an isolation unit of five single rooms and four single-bedded, two two-bedded, four four-bedded and one sixbedded wardlets shows what can be accomplished, for in a year's turnover there were only three instances of secondary infection among 74 infants under 18 months while the cross-infection rate among the older children in the small wards was 6 per cent. Advice about the sources, modes of spread and methods of control of infection in hospital is given in the Medical Research Council's War Memorandum, No. 11. Although improved isolation accommodation and better equipment are sorely needed in most hospitals, much could be accomplished if each hospital had its own crossinfection committee composed of clinicians, nurses and bacteriologist to overhaul the existing machinery and to devise practicable and effective procedures for dealing with incidents such as a case of diphtheria or scarlet fever or measles or Sonne dysentery in an open ward. Nurses should also be given a short course in applied bacteriology early in their training so that they can intelligently carry out the ritual which is needed if our hospitals are to do the sick no harm.

Residential and day nurseries need expert super- 
vision, and both the paediatrician and the bacteriologist should be co-opted to handle the problem of infection which can do so much harm among young children in nurseries. Residential nurseries are, I suppose, required in any large town but large wards or rooms should be banned, and admission of infants under one year of age should not be made easy. The unique experience in the Greater London area of a rising mortality rate from gastro-enteritis may be partly attributable to the necessity to provide residential accommodation for a large number of young children (Gairdner, 1945). The unwanted illegitimate child illustrates well the hazards that attend the infant deprived of parental care. For example, the illegitimate London child has a 1 in $\mathbf{4 0}$ chance of dying of diarrhoea before it reaches its first birthday. Yet Birmingham has shown that, by proper supervision of these unfortunates, their mortality rate can be reduced to a lower level than that of legitimate children.

In the day nursery exogenous infections like measles, whooping cough and Sonne dysentery are responsible for much of the sickness, and methods of controlling these infections in semi-closed communities are now available in the use of convalescent measles serum or gamma globulin, pertussis vaccine and antiserum and chemoprophylaxis. Great benefit would follow if the age of attack of infections like measles could be postponed, for two-thirds of the deaths from this disease occur between six months and two years of age. The childhood fevers are mostly brought into the home from school, and an interesting investigation in Philadelphia suggests that epidemic spread of measles and chicken-pox among children in school can be largely controlled by continuous irradiation of the classrooms with ultra-violet light through the winter months (Wells, Wells and Wilder, 1942). If so, the age of attack could be postponed and children could have their attack of measles when it is least likely to do them harm.

If I may close in a critical mood, I would say that in the past the paediatrician has been too much concerned with infection in the individual child and not enough with infection in the child community. With chairs of child health being established in almost every University city, there will be many opportunities to correct this fault if and where it exists. I have tried to indicate some of the problems that need to be tackled both in the individual infant and in the community and I can only hope that George Frederic Still would have nodded approval of my effort. In the words of Alva
Myrdal: 'As soon as the economic machinery has been repaired in a provisionary way so that international exchange is again functioning and the masses of workers are given employment and bread, a new interest will attach to productive investment in a nation's chief economic asset: children and their health and capabilities.'

\section{REFERENCES}

Alexander, M. B., and Eiser, Y. (1944). Brit. med. J., 2,425 .

Anderson, T. (1943). Ibid., 2, 779.

Bray, J. (1945). J. Path. Bact., 57, 239.

Cruickshank, R. (1933). Lancet, 1, 680.

Ebbs, J. H., and Kelley, H. (1942). Arch. Dis. Childh., 17, 212.

$\longrightarrow$, and Mulligan, F. (1942). Loc. cit., 217.

Ehrich, W. E., and Harris, T. N. (1942). J. exp. Med., 76, 335 .

Gairdner, P. (1945). Arch. Dis. Childh., 20, 22.

Gale, E. F. (1944). Brit. med. J., 1, 631.

Glover, J. A., and Wilson, J. (1932). Loc. cit., 2, 506.

Graham, S. G. (1944). Proc. Nutrit. Soc., 2, 65.

Gröer, F., and Kassowitz, K. (1919). Z. Immun Forsch. T1. 1. Orig., 28, 327.

Grulee, C. G., Sanford, H. N., and Herron, P. H. (1934). J. Amer. med. Ass., 103, 735.

Harris, T. N., Grimms, E. M., and Ehrich, W. E. (1945). J. exp. Med. 81, 73.

-, and Stokes, J. (1945). Amer. J. med. Sci., 209, 152.

Hendry, E. (1942). Arch. Dis. Childh., 17, 111.

Hickmans, E. M., Finch, E., and Tonks, E. (1943). Ibid., 18, 96.

Jacoby, N. M. (1944). Ibid., 19, 26.

Kuttner, A., and Ratner, B. (1923). Amer. J. Dis. Child., 25, 413.

MacGregor, A. (1943). Edinb. med. J., 50, 332.

Mackay, H. M. M. (1931). Med. Res. Coun. Spec. Rep. Series: No. 157., Lond.

Mackintosh, J. M. (1943). Proc. Nutrit. Soc., 2, 58.

Med. Res. Coun. (1944). War. Memo. No. 11: Lond.

Miller, R. A. (1942). Arch. Dis. Childh., 17, 198.

Myrdal, A. (1945). Nation and Family, Lond.

Pickerell, H. P., and Pickerell, C. M. (1945). Brit. med. J., 1, 159.

Report on Infant Mortality in Scotland (1943). Dept. of Health for Scotland.

Robinson, M. (1939). Arch. Dis. Childh., 14, 259. (1941). Ibid., 16, 31.

(1942). Ibid., 17, 23

Sauer, L. W. (1935). J. Pediat., 6, 753.

Smellie, J. M. (1939). Lancet, 1, 969.

Titmus, R. M. (1943). Birth, Poverty and Wealth, Lond.

Watson, M. (1937). J. Hyg., Camb., 37, 396.

Wells, W. F., Wells, M. W., and Wilder, T. S. (1942). Amer. J. Hyg., 35, 97.

Wright, G. P., and Wright, H. P. (1942). J. Hyg, Camb., 42, 451.

Wright, J., Cruickshank, R., and Gunn, W. (1944). Brit. med. J., 1, 611 .

Young, W. F., and McCance, R. A. (1941). J. Physiol., 99, 265. 99, (1942). Arch. Dis. Childh., 17, 65. 